\title{
Interoperable XML Messaging System for Tactical Data Link
}

\author{
Hongjae Kim*, Sangyoon $\mathrm{Oh}^{* *}$ \\ 전술데이터링크 상호운용을 위한 XML 기반 메시징 시스템
}

\author{
김 홍 재*, 오 상 윤 **
}

\begin{abstract}
Tactical Data Links are standardized radio communication data links for military armed forces and used to transmit and receive data. Because they are the core elements of achieving information superiority in a NCW environment, various kinds of TDL are used by the Korean armed forces. Operating various types of TDL is very helpful in getting more information; however, at the same time, it is hard to integrate and make them co-operate with other TDLs or CAISR systems. In this paper, we propose a XML based messaging system to make various types of TDL interoperable in a NCW environment. For the messaging system between TDL and CAISR systems, we define XML message processing interfaces and suggest binary XML for serialization to save transmission loads over constrained military communication bandwidth. Our experiment results show that the TDL message can be transformed into generalized XML data that is interoperable with other TDLs and binary XML serialization, and it saves parsing and transmission time.
\end{abstract}

- Keyword : XML messaging, XML, Binary XML, Interoperability, Tactical Data Link

\section{요 약}

전술데이터링크(TDL)는 전술정보 및 상황정보를 실시간으로 교환하기 위한 통신체계이며, 네트워크 중심전 $(\mathrm{NCW})$ 에서 정보우위를 점하는데 필요한 주요 요소이다. 한국군에서도 정보우위를 위해 다양한 전술데이터링크를 사용 중이나 이러한 다양한 전술데이터링크의 사용은 전체 C4I 시스템의 통합과 다른 전술데이터링크와의 연동을 어렵게 만들어 전체 시스템의 상호운용개념에 반하게 되는 문제점을 가진다. 본 논문에서는 네트워크 중심전 환경 에서 다양한 전술데이터링크간의 상호운용이 가능한 XML 기반의 메시징 시스템을 제안한다. 제안 시스템은 전술 데이터링크와 $\mathrm{CAI}$ 시스템에서 사용하는 메시지와 인터페이스를 XML로 정의하여 이용한다. 그리고 제한된 네트워 크 대역폭을 가지는 군 환경을 고려하여 바이너리 XML을 통해 네트워크 부담을 줄이는 것을 제안한다. 본 논문에

- 제1저자 : 김홍재 교신저자 : 오상윤

- 투고일 : 2010. 11. 01, 심사일 : 2010. 11. 16, 게재확정일 : 2011. 01. 23.

* 아주대학교 NCW학과(Dept. of NCW, Ajou University)

** 아주대학교 정보 및 컴퓨터공학부(School of Information and Communication Engineering, Ajou University)

* This research was jointly supported by the MKE(The Ministry of Knowledge Economy), Korea, under the ITRC(Information Technology Research Center) support program supervised by the NIPA(National IT Industry Promotion Agency" (NIPA-2011-(C1090-1121-0011)) and Ajou university research fellowship of 2010(S-2010-G0001-00087) 
서는 실험결과를 통해 전술데이터링크 메시지가 XML 스키마에 정의된 대로 상호운용이 가능한 메시지 형태로 변 환됨과 바이너리 XML serialization을 통해 파싱과 전송시간의 감소를 가져오는 것을 보여준다.

- Keyword : XML 메시징, XML, 바이너리 XML. 상호운용성, 전술데이터링크

\section{Introduction}

In modern warfare, information superiority is an important factor what can rapidly achieve situation awareness and decision making in the battlefield. As a result, information superiority enables us to favorably impact combat operations. Networks Centric Warfare (NCW)[1] is generally thought to the link platforms (e.g., aircraft, warship) into one, share awareness networks in order to obtain information superiority, get inside the opponent's decision cycle, and end conflict quickly. In contrast to NCW, traditional warfare is considered to be Platform Centric Warfare (PCW) that cannot link with other platforms and cannot create a shared awareness network. Thus, NCW effects are more effective than PCW[2]. So many armed forces, including the Korean, try to convert $\mathrm{PCW}$ into $\mathrm{NCW}$ to improve their military capabilities.

Tactical Data Link (TDL) is a standardized radio communication data link that can communicate tactical information about battle space between combat systems, CC (Command and Control) systems and other information systems[3]. TDL is a key element for achieving NCW. By using TDL, we can share situation awareness and make good decisions. TDL was developed the 1950s and was used by other countries (including U.S. and U.K), and in 1997, the Korean armed forces started using TDL by the navy to operate the Korean Naval Tactical Data System (KNTDS), which uses Link-11 to communicate tactical information.

U.S. and NATO currently use various TDLs (like Link-11, VMF, etc); the Korea armed forces use Link-11, Link-14, Link-16 and ISDL (Used in KNTDS for wired environment and similar to Link-11), and they are developing Link-K[4].
However, most TDLs are predefined by their own standard documents. Table 1 shows the standard document of TDLs. Standard documents define their own message formats and the way of communicating tactical information. Moreover, depending on TDL, the application is implemented by different programming languages. So it is hard to make integrate various TDLs with other TDLs or CAISR (command, control, communications, computers, intelligence, Surveillance and Reconnaissance) systems. This problem occurs more frequently during allied operations or joint operations when an operation needs various platforms and TDLs, and this problem makes it hard to archive Information superiority.

표 1. 전술데이터링크 표준 문서 Table 1. Standard documents of TDLS

\begin{tabular}{|c|c|c|}
\hline TDL & U.S. & NATO \\
\hline Link-1 & - & STANAG 5501 \\
\hline Link-4 & ML-STD 6004 & STANAG 5504 \\
\hline Link-11 & ML-STD 6011 & STANAG 5511 \\
\hline Link-11B & ML-STD 6011 & STANAG 5512 \\
\hline Link-14 & - & STANAG 5514 \\
\hline Link-16 & ML-STD 6016 & STANAG 5516 \\
\hline Link-22 & - & STANAG 5522 \\
\hline
\end{tabular}

The current tactical message communication method between TDL, TDL application and CAISR system is implemented by Point-To-Point conversion that does not have flexibility[5]. Thus, it is difficult to manage when using various TDLs in integrated environments and hard to extend them to other new systems.

$\mathrm{XML}$ is text based markup language that can define and exchange specific data[6]. When we define a TDL message by using XML, we can use an interoperable data format for TDL messages. The messaging system with XML message format has been used to provide a flexible and agile messaging 
between distributed nodes. And targeted levels are different, but there are several XML messaging systems which use XML message such as XMPP (Extensible Messaging and Presence Protocol), XML based Publish Subscribe system. Also XML provides scalability for TDL, TDL applications and CAISR systems because of XML namespace that provides a method to avoid name conflicts[7].

Military network bandwidth is constantly being developed, but it is still limited when compared to commercial bandwidth and because of additional overhead due to security, reliability and add Ad-Hoc functions. And because of XML's verbosity, when we use XML with TDL messages in a military domain, there are some limitations (e.g., file size, parsing).

In this paper, we propose the Interoperable $\mathrm{XML}$ messaging system for TDLs. For meeting the system requirements mentioned above, we suggest a message interface for interoperability between systems (TDL, TDL applications and CAISR systems) and binary XML for military networks that have low bandwidth. Our suggested design for a XML messaging system is specialized for efficiency without sacrificing interoperability which make difference between our proposal and other XML based messaging system.

According to the results shown in this paper, we can confirm the flexibility of XML-based messages, performance Improvement by using binary XIM, and we can expect our system effects when adopting it into other NCW systems.

We first introduce the cases of XML used in military domains and countries projects or systems for achieving TDL interoperability in Section 2. In Section 3, we present the XML based TDL message used in our system and describe our implementation. We present our system's efficiency and suitability based on our evaluation results in Section 4. Section 5 concludes the paper.

\section{Related work}

In recent years, XML has been widely applied to military domains. Especially, the U.S. Air Force focuses on applying XML in NCW environments and CAISR systems and on using binary XML for resolving $\mathrm{XML}$ limitations. In this section, we present a brief introduction of binary XML, and we present cases of military domains and other countries' projects aimed at achieving TDL interoperability.

\section{Binary $X M L$ use in military domains}

There are some cases of binary XIM usage to reduce overhead due to $\mathrm{XML}$ verbosity. In this section, we present a brief introduction of binary $\mathrm{XML}$ and its usage in military domains. Binary XML is adapted to our messaging system for military networks with limited bandwidth.

\subsection{Binary XML}

XML has benefits such as compatibility and independence, but because of XML's text based characteristics, XML documents also have limitations. First, an XML document is larger than equivalent files in other formats[8]. So XML needs more memory, storage and network bandwidth. Second, XML needs additional parsing and transformations that make to limit the use of XML in mobile devices such as mobile phones and PDAs[9].

To overcome such limitations, Binary XMLs were presented such as Fast Infoset[10] and Efficient XML Interchange (EXI)[11]. Especially W3C created XML Binary Characterization Working Group (XBC WG) what published some documents including XML Binary Characterization Use Cases[12]. And in XML Binary Characterization Use Cases, they describe Military Information Interoperability as a case of binary XML usage. 


\subsection{Efficient XML Interchange (EXI)}

The EXI format has been produced by the W3C EXI Working Group based on the conclusions of the XBC WG. EXI makes use of structural information and separates between XML structure and payload data, and the string tables are generated for encoding. String tables have variable string length and indexes[13],[14]. The body of EXI document is composed of predefined sequential EXI events (e.g., start document, end document).

\subsection{Fast Infoset (FI)}

FI is a binary representation of XML document standardized by ITU-T[15]. FI document can be smaller in size and faster to parse and serialize than equivalent XML documents. Strings are tokenized FI at their first occurrence and make Vocabulary tables. If the tokenized string occurs again, then FI converts the string into index[14],[16]. Through this conversion, the XIML document can be smaller in size.

\subsection{XML Schema based Binary Compression (XSBC)}

$\mathrm{XSBC}$ is a result of the work of a U.S. Naval Postgraduate School (NPS) thesis that can defines dynamic protocol used in networked virtual environments. XSBC tokenizes tags and replaces them with integer values. It then tries to reduce the data within the tag to the simplest possible data type. NPS's experiment results show that XSBC provides better compression than FI on files as large as $500 \mathrm{kB}$ and $\mathrm{FI}$ parses files more quickly than $\mathrm{XSBC}$ on most files[17].

\subsection{Binary XML research in the U.S. Air Force}

In terms of NCW, the U.S. Air Force needs seamless interoperability between the warfighting elements for sharing information, situational awareness and commander's intent. So they are researching the adoption of XML and improving the interoperability in military domain by using Internet Protocol, Web browser, Web Service, Service Oriented Architecture, etc[18].

For data exchange between different systems,
U.S. Air Force aims at creating common vocabulary by using XML schema to create interoperable data exchange. But airborne network has limited bandwidth, and using $\mathrm{xml}$ requires additional overhead. So they try to adopt binary XML that can reduce additional overhead. The U.S. Air Force needs a binary standard that satisfies their requirements with widespread commercial support.

\section{2. $\mathrm{XML}$ use in messaging systems}

Recently XML are widely used in various domains. In this section, we present XML use cases in messaging systems.

\subsection{XMPP}

$\mathrm{XMPP}$ is streaming protocol for message oriented middleware based on XML. XMPP was originally named Jabber and developed in 1999 by Jabber open source community. XPPP's most benefits are can be extensibility flexibility. By using MXL, user can build own custom functionality on top of XMPP. To maintain interoperability, common extensions are managed by XMPP Software Foundation. But XMPP has problem with binary data transfer and try to solve that problem.

\subsection{XML based Publish/Subscribe System}

Publish/Subscribe System is a kind of messaging pattern. In Publish/Subscribe System, messaging publishers do not care about subscribers and just send message through Publish/Subscribe channels. And subscribers can receive the messages based on their subscriptions. There are some Publish/Subscribe Systems are researched and developed which use XML[18]. This XML messages have flexibility and XPath or XQuery provides more efficient ways for subscriber's subscriptions.

\section{Research on interoperability for military systems}

Integrating and making various TDLs co-operated has been a issue to the countries who operates them. We present other countries projects or systems that aim at achieving TDL interoperability. 


\subsection{Common Link Integration Processing (CLIP)}

The U.S. Navy and Air Force are collaborating on the CLIP initiative. CLIP is a software solution that has an open architecture software-based on common tactical message processing and integration capability with applications across various military platforms and installations[20]. So, CLIP will reside on any operating system or hardware, and CLIP will provide the interface to current TDLs (including Link-16, Link-22 and VMF) as well as under development TDL systems (TTNT, JTRS, WNW).

Fig. 1 shows that CLIP allows gateway and data-forwarding functionality among TDLs and emerging service oriented architectures; CLIP also supports the Global Information Grid (GIG). CLIP reduces the life-cycle maintenance by making changes and upgrades common to multiple platforms without the need for costly updates to their host operating systems[21].

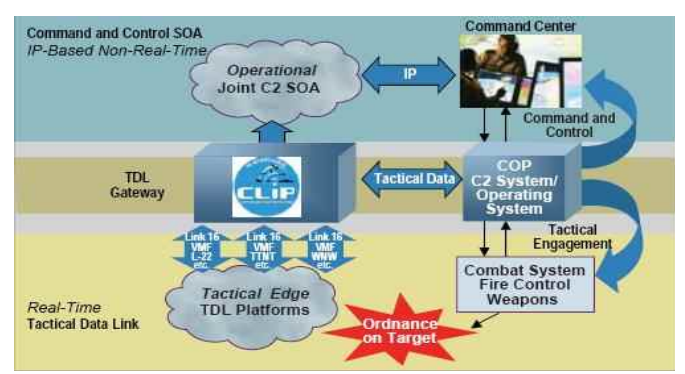

그림 1. CபP 운영 개념

Fig. 1. CLP operation

\subsection{Networked Interoperable Real-time Information Services (NIRIS)}

The North Atlantic Treaty Organization (NATO) has performed work to convert tactical link data into an XML format for distribution to command and control centers. The data format transmitted in the tactical environment is the same, but command centers convert the data into XIM using software known as NIRIS that fuses data to create a common operating picture (COP) and has also been modified to act as a server for various web services. With this architecture, a simple web application contacts NIRIS via a secure VPN over the internet and is able to graphically display TDL data or perform whatever task the web application requires[17]. By using NIRIS, non TDL platforms that do not have TDL equipments can receive and transport TDL data.

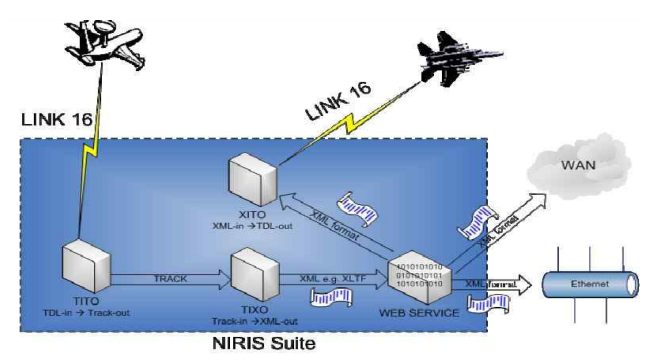

그림 2. NIRIS 웹 서비스를 통한 Link-16 데이터 전파

Fig. 2. Link-16 Data Transport through NIRIS's Web Service

\subsection{Data Links and Tactical Messaging Interoperability Hub $(\mathrm{TM} H)$}

$\mathrm{TMIH}$ is an IBM solution for achieving facilitates interoperability between platforms that have TDL legacy systems and platforms or sites that are TCP/IP-enabled[22]. By adopting SOA and XML, TMIH offers low development cost, ease of maintenance and platform independence features. TMIH adds an XML adaptor to DTL data, and when it is loosely coupled with enterprise service bus, it can exchange TDL data between the situation awareness portal and TDL.

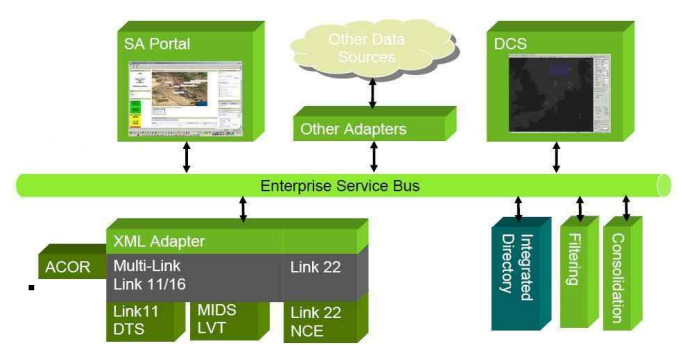

그림 3. $\mathrm{TMH}$ 시스템 이키텍처

Fig. 3. System Architecture Overview of $\mathrm{TMMH}$ 


\section{Interoperable XML Messaging System for TDLs}

In this section, we present and interoperable XML messaging system for TDLs. Our system uses XML based data structure and programming interface to exchange TDL data between other TDLs, applications and CAISR systems. Moreover, we use XML schema to define the interface.

\section{TDL features and limited interoperability}

TDLs exchange data according a predefined message based on its own standard document like MIL-STD and STANAG. For example, a Link-16 message is composed of words with 70bits size, and each word is composed of fields[23]. Table 2 shows Link-16 Air Track Message (J2.2E0) A word is 70bits of size and contains six fields (Word format, Spare, Latitude, etc.)[24].

표 2. 대공표적 메시지 워드 Table 2 Air Track Message Word(J2.2EO)

\begin{tabular}{|c|c|}
\hline Field & Bits \\
\hline Word format & 2 \\
\hline Latitude & 23 \\
\hline Longitude & 24 \\
\hline Spare & 1 \\
\hline Course & 9 \\
\hline Speed & 11 \\
\hline
\end{tabular}

Thus, TDLs data exchange is limited by predefined standard documents when data is exchanged with other TDLs and CAISR systems. However, modern warfare is mostly joined or combined operations that require various TDL data. To resolve this problem, we can use only one TDL. However, based on its purpose, each DTL has different features; furthermore, when considering joint operations with other countries, it is inappropriate. Then, creating a Point-to-Point converter (e.g., convert Link-16 message to Link-11 message) can be another way, but it still has a problem. When $\mathrm{N}$ TDLs exist, the converter $\mathrm{N} *(\mathrm{~N}-$ 1) will need[25]. Fig. 4 shows that the number of required converters base on number of TDLs, when five TDLs exist, must be twenty $(5 * 4)$ converters, and when more TDLs or applications are needed, we need more converters.

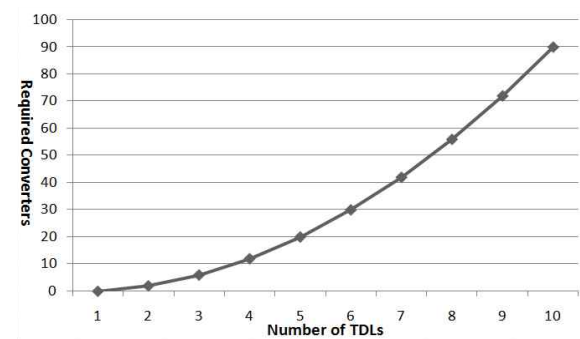

그림 4. 전술데이터링크 숫자에 따른 컨버터 소요

Fig. 4. Required converters base on number of TDLS

Moreover, the message identification problem and duplicated data problem can occur when TDL uses the same message name between TDLs, applications and CAISR systems. Fig. 5 shows that if the application receives an Air Track message and there are two existing TDLs that have Air Track messages; because of message name collisions, it is difficult for the application to identify messages (e.g., the source)

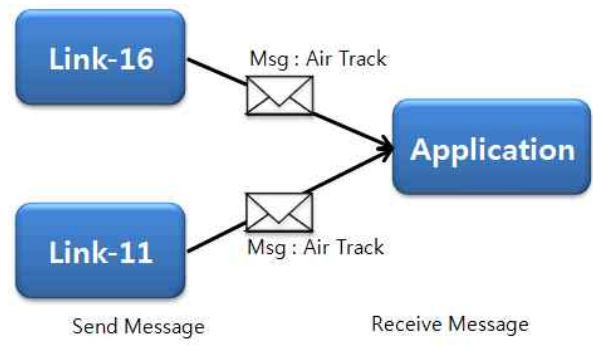

그림 5. 전술데이터링크 메시지 이름 충돌

Fig. 5. Message name collision in TDLs

2. Benefits and limits of using XML messages

There are several benefits of using $\mathrm{XML}$ 
messages. First, Messages code in XML is easy to read, understand. Second, XML can Self-describe and there is no fixed set of tags. New tags can be created as they are needed. Third, we can use XML as a data representation and messaging standard. Fourth, we can avoid message name collision by using XML namespace[26]. But unfortunately there are some problems with XML. Because of XIL's verbosity, XIL documents have bigger file size, needs more memory and needs additional parsing. These problems can effect to our XML messaging system. This is why we use Binary XML for our system's performance.

\section{XML messaging system for TDLs}

Our proposed XML messaging system uses XML messages for exchanging TDL data. Fig. 6 shows a system consisting of TDL msg coordinator, XML mngr, Binary XML mngr and Msg transceiver module.

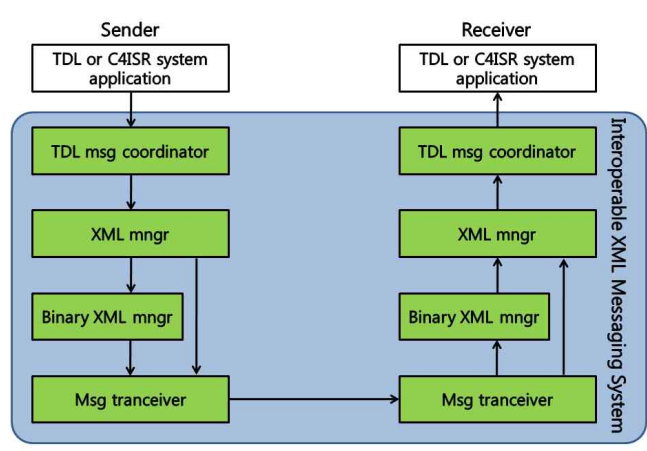

그림 6. XML 메시징 시스템 구조

Fig. 6. XML messaging system structure

TDL msg coordinator connects with TDL or CAISR applications, receives TDL data and decides whether or not to make Binary XML messages. After deciding, it delivers data (including the decision) to the XIM mngr. If it receives TDL data from the XML mngr, TDL msg coordinator delivers TDL data to TDL or CAISR applications.

XML mngr translates between TDL data and $\mathrm{XML}$ messages. When translating is over, $\mathrm{XML}$ mngr delivers the XML message to the Msg transceiver or TDL msg coordinator. If Binary XML is needed, XML mngr delivers the XML message to the Binary XML mngr instead of XML mngr.

Binary XML mngr translates between XML messages and Binary XIL messages. After translation, Binary $\mathrm{XML}$ mngr delivers the messages to the proper module (Msg transceiver or XML mngr).

Msg transceiver Sends the delivered messages (XML or Binary XML) to other XML messaging systems, and it checks file extension that is sent by other $\mathrm{XML}$ messaging systems and delivers the messages to the proper module (XML or Binary XML mngr).

Fig. 7 shows XML message structure used in our XML messaging system. XML messages are divided into header and body. The header has message information and is divided into five fields (Msg class, Msg name, Silimar msg, Msg purpose field). Body contains the Msg content field that has TDL message data that is used in applications.

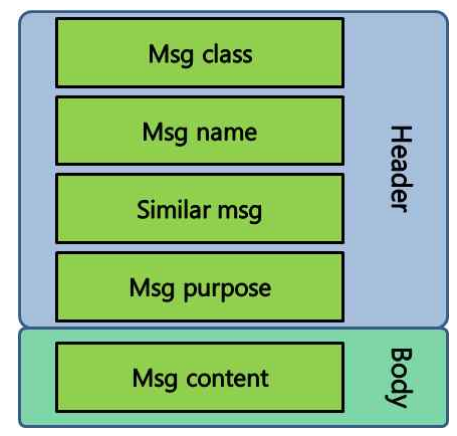

그림 7. XM 메시지 구조

Fig. 7. XM message structure

Message Class: TDL type (eg., Link-11, Link-16, etc.)

Message Name: TDL message name

Message Purpose: Purpose and function of TDL message

Similar Message: Message name that has a similar purpose or function in other TDLs.

By using XML message that contains TDL data, applications that can use TDL data become more flexible. When we use XML, namespace can avoid message name collision. 


\section{4. $X M L$ message for TDL data exchange}

XML Schema provides a definition of the structure and contents of an XML file[27]. XML Schema defines the order of the elements, name and type of elements, and name and type of attributes[28]. Moreover, it can define its own data type. By using XML Schema, we can define TDL messages. Fig. 8 shows the XML schema that defines Air Track message (shown in table 2).

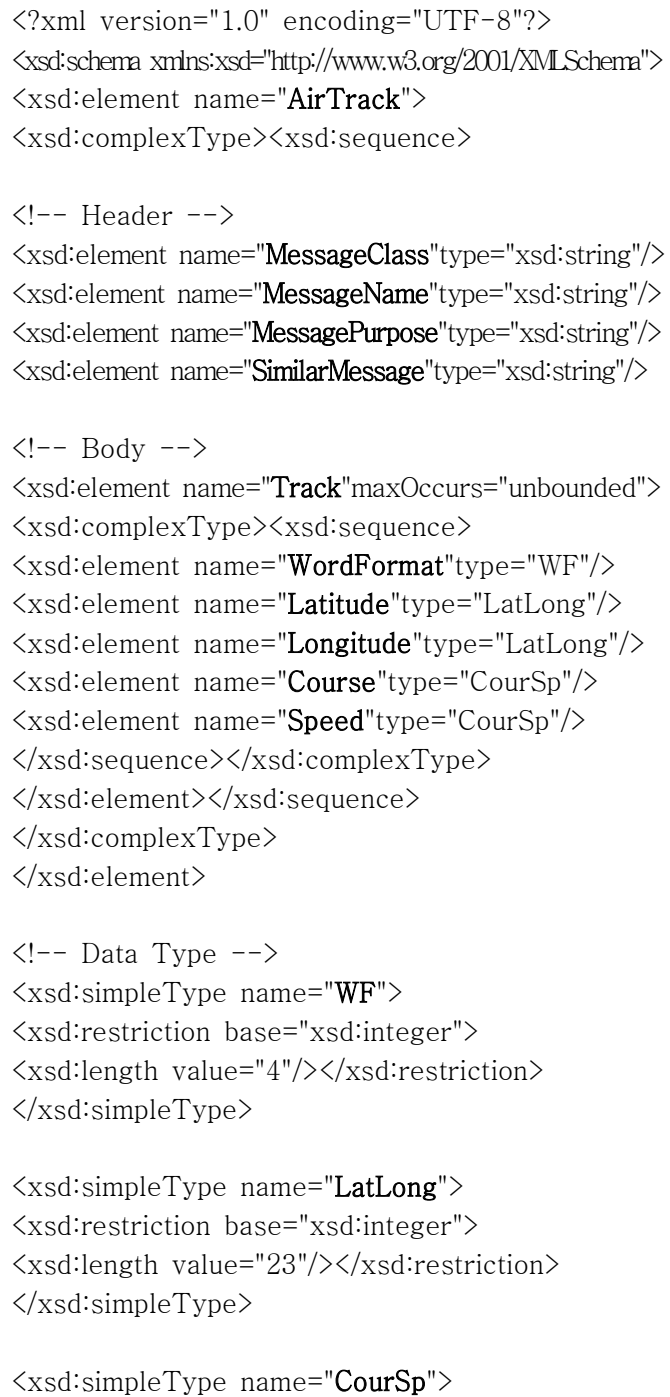

$\langle$ xsd:restriction base="xsd:integer" $\rangle$

$\langle x$ xd:length value $=" 10 " /\rangle\langle$ xsd:restriction $\rangle$

$</$ xsd:simpleType $>$

$</$ xsd:schema $>$

그림 8. XML 스키마로 정의한 대공표적 메시지

Fig. 8. XML Schema which define Air Track message

In Fig. 8, root element (AirTrack) means that the TDL message name and root element has five child elements (MessageClass, MessageName, MessagePurpose, SimilarMessage and Track). The Track element means message contents. So, the track element has five child elements (WordFormat, Latitude, Longitude, Course and Speed). After we have defined the elements, we define data type.

Fig. 9 shows an XML document with an Air Track message defined by XML schema. By declaring XML namespace, we can recognize that this XIML document was written based on AirTrack schema. So, even if other TDL uses the same message name or element name, we can avoid message name collision.

$\langle$ ?xml version="1.0" encoding="ISO-8859-1"?〉

<AirTrack xmlns:xsi = "http://www.w3.org/2001/XML

Schema-instance" xsi:noNamespaceSchemaLocation =

"AirTrack,Link-16.xsd">

$\langle$ !-- Header --$\rangle$

$\langle$ MessageClass $>$ Link $-16</$ MessageClass $>$

$\langle$ MessageName $>$ AiarTrack $</$ MessageName $>$

$<$ MessagePurpose $>$ Notify Track'sInformation

$</$ MessagePurpose $>$

$\langle$ SimilarMessage $>$ AirTrack.Link $-11</$ SimilarMessage $>$

$\langle!--$ Body --$\rangle$

$\langle$ Track $\rangle$

<WordFormat $>1111<$ WordFormat $>$

〈Latitude $>10101010101010101010101</$ Latitude $>$

〈Longitude〉10101010101010101010101</Longitude〉

$\langle$ Course $>1010001010</$ Course $\rangle$

$\langle$ Speed $>0101110101</$ Speed $\rangle$

$\langle/$ Track $\rangle$

$<$ AirTrack $>$

그림 9. 대공표적 메시지 XML 문서

Fig. 9. XML document which has Air Track message 
5. Message serialization by using binary $\mathrm{XML}$

Because of XML's verbosity, XML documents have bigger file size and need additional parsing processes. Using XML can decrease the proposed $\mathrm{XML}$ messaging system performance. However, binary XML documents can be smaller in size and faster to parse and serialize than equivalent XML documents. Our proposed XML messaging system has two kinds of binary XML, EXI and FI.

\section{Evaluation and results analysis}

Our XML messaging system can use both XML and binary XML for exchanging TDL data. In this section, we present a performance comparison between XML and binary XML. The XML messaging system for tactical data link that can improve interoperability between applications. However, because of XML's verbosity, XML documents can be heavy and need additional parsing processes. For example, Link-16 Air Track message size (As shown in Table 2) is 70 bits, but the message size is 395 bytes when TDL messaging is written in XML (As shown in Fig. 9). To overcome XML's limitations, we use binary XML. To compare performance between $\mathrm{XML}$ and binary XML, we evaluate the file size and process time of both XML and Binary XML.

\section{Evaluation Setup}

When CAISR system exchanges TDL data, it gathers hundreds of TDL data and makes one message. So, before the evaluation, we create five XML files (As shown in Table 3) that have different numbers of messages. These messages are used in our XML messaging system for checking file size and calculating process time. During the evaluation, we use two nodes with specifications as shown in Table 4.
표 3. 대공표적 메시지 XM 파일

Table 3. Aitrack message

\begin{tabular}{|c|c|c|}
\hline File name & $\begin{array}{c}\text { Number of } \\
\text { message }\end{array}$ & File size(KB) \\
\hline $100 . x m l$ & 100 & 20.66 \\
\hline $200 . x m l$ & 200 & 40.98 \\
\hline $300 . x m l$ & 300 & 61.29 \\
\hline $400 . x m l$ & 400 & 81.60 \\
\hline $500 . x m l$ & 500 & 101.91 \\
\hline
\end{tabular}

표 4. 노드 사양

Table 4. Nodes Specifications

\begin{tabular}{|c|c|c|}
\hline CPU & Node1 & Node2 \\
\hline RAM & $\begin{array}{c}\text { Intel Core2 } \\
\text { Quad 2.40GHz }\end{array}$ & $\begin{array}{c}\text { Intel Xeon } \\
\text { Quad 1.6 GHz X 2 }\end{array}$ \\
\hline OS & $3.5 \mathrm{~GB}$ & $8 \mathrm{~GB}$ \\
\hline $\begin{array}{c}\text { Whdows7 } \\
\text { 32bit } \\
\text { version }\end{array}$ & 1.6 .0 & Fedora12 64bit \\
\hline
\end{tabular}

For process time comparison, we considered two kinds of processes. One just uses XML and the other uses XML with binary XML.

First, using the XML process is simple. Node 1 sends XML file to Node 2 and Node 2 parses the $\mathrm{XML}$ file that is from Node 1. After parsing, XML process is over. Thus, the formula for XML process time $(\mathrm{T})$ is as follows:

$$
\mathrm{T}=\mathrm{T}_{\mathrm{t}}+\mathrm{T}_{\mathrm{XP}}
$$

$-T_{t}=$ File transmission time

$-\mathrm{T}_{\mathrm{XP}}=\mathrm{XML}$ file parsing time 


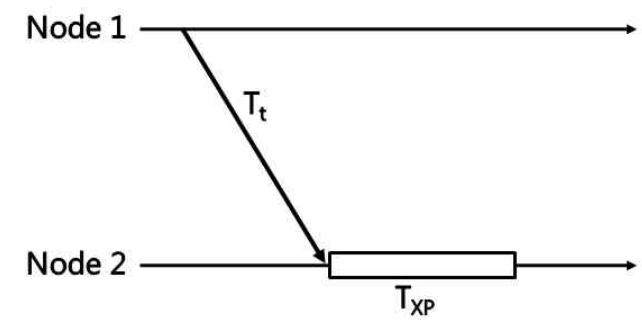

그림 10. XML 프로세스

Fig. 10. XML process
Second, using XML with a binary XML process includes translate time for binary XML. Node 1 translates the XML file into a binary XML file. Node 1 then sends binary the XML file to Node 2, and Node 2 parses the binary XML file. After parsing, Node 2 translates the Binary $\mathrm{XML}$ file into $\mathrm{XML}$ file, and then the XML with binary $\mathrm{XML}$ process is over. The formula for $\mathrm{XML}$ with binary $\mathrm{XML}$ process is as follows:

$$
\mathrm{T}=\mathrm{T}_{\mathrm{XToB}}+\mathrm{T}_{\mathrm{t}}+\mathrm{T}_{\mathrm{BP}}+\mathrm{T}_{\mathrm{BToX}}
$$

- $\mathrm{T}_{\mathrm{XToB}}=\mathrm{XML}$ to Binary XML translation time

$-\mathrm{T}_{\mathrm{t}}=$ File transmission time

$-\mathrm{T}_{\mathrm{BP}}=$ Binary XML file parsing time

- $\mathrm{T}_{\mathrm{BTOX}}=$ Binary XML into XML translation time

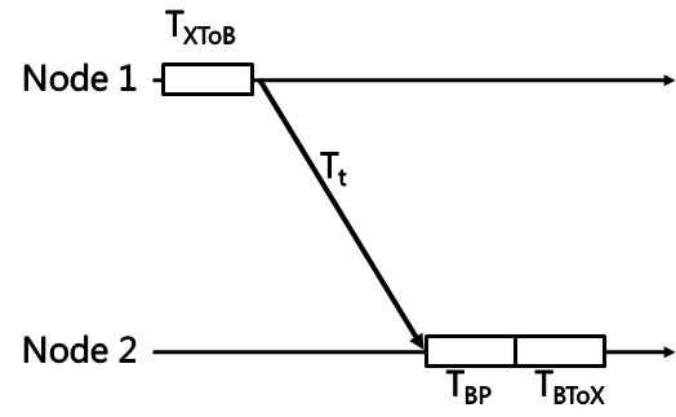

그림 11.Binary XM을 포함한 XM 프로세스 Fig. 11. XML with binary XM process

\section{Evaluation Results}

Table 5 shows file size comparison between XML and binary XML. Through binarization, binary XML can compress file size by more than $50 \%$, and EXI had a smaller file size than FI.
표 5. 파일 압축 결과 (KB)

Table 5. File size comparison (KB)

\begin{tabular}{|c|c|c|c|}
\hline File name & XML & Fl & EXI \\
\hline 100.xml & 20.66 & 9.82 & 7.72 \\
\hline $200 . x m l$ & 40.98 & 19.24 & 15.12 \\
\hline $300 . x m l$ & 61.29 & 28.28 & 22.18 \\
\hline $400 . x m l$ & 81.60 & 37.32 & 29.21 \\
\hline $500 . x m l$ & 101.91 & 46.12 & 36.05 \\
\hline
\end{tabular}

Fig. 12 shows the results of the XML process time and XML with binary XML process. According to the results, XML with binary XML process time is shorter than XIL process, and FI shows shortest process time during evaluation.

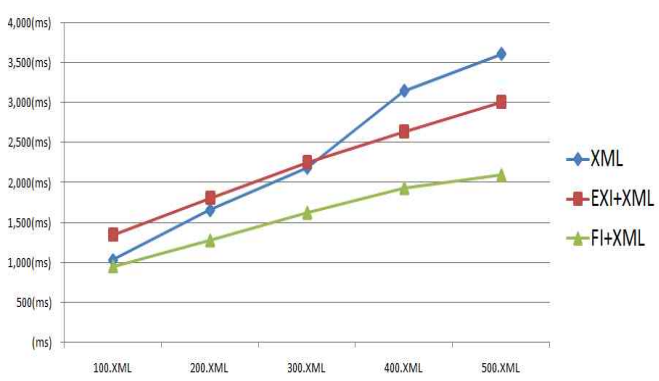

그림 12 프로세스 시간 결과

Fig. 12. Process time comparison

Fig. 13 shows transmission time depends on file size during our evaluation. For example, it spends $1845 \mathrm{~ms}$ when Node 1 sends 500.XML to Node 2. But, after translating XML into binary XML, it spends $848 \mathrm{~ms}$ (FI) and 668ms (EXI).

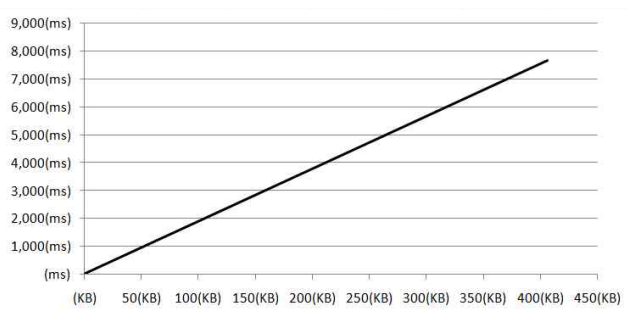

그림 13. 파일 크기에 따른 전송 시간

Fig. 13. Transmission time depend on file size 
Fig. 14 shows the results of XML processing time and XML with binary XIL process except transmission. According to the results, the $\mathrm{XML}$ with binary XML process spends more time than the XML process. However, comparing XML to EXI with XML, time differences are relatively small. Therefore, more important factor in our process time is the file size rather than translation time and parsing time.

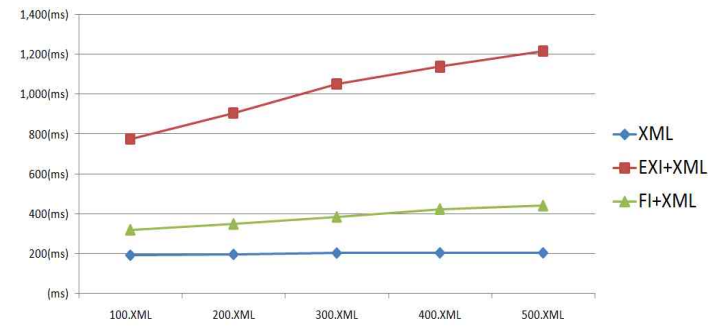

그림 14. 전송 시간을 제외한 프로세스 시간

Fig. 14. Process time results except transmission

Through evaluation, we found that when using binary XML, although additional time is required, it can reduce processing time and improve the performance of XML messaging system. Moreover, binary XML performance can be better because binary XML are still ongoing projects.

\section{Conclusion}

NCW is thought to be the linking of platforms into one, shared awareness network in order to obtain information superiority, and TDL is a key element for achieving NCW. However, most TDLs are predefined by their own standard documents, and applications are implemented by different programming languages. So, it is hard to integrate and co-operate together with other TDLs or CAISR systems.

There are several XML messaging systems which use XML message such as XIMP, XML based Publish Subscribe system But the domain we target is the military SW, thus including transport layer protocols are not perfectly fit into this picture. For example, models for Link-16 and Link-22 can not be categorized into one of OSI 7 layers protocols. And many of military SW are treated as confidential or secret, it is difficult to find comparison targets. So we need to research or find solution, even if idea is same. Because domain is different and it has different constraints.

In this paper we proposed Interoperable XML messaging system for TDLs. Our system uses the XML based data structure and programming interface for exchange TDL data between other TDLs, applications and CAISR systems. Morevoer, our system uses XML schema to define an interface, uses XML messages as TDL data. This XML schema and message enable applications to use TDL data to gain more flexibility, and XML namespace provides a way to avoid message name collisions.

However, because of XML's verbosity, XML documents have bigger file size and needs additional parsing process. Using XML can decrease the proposed XIL messaging system performance. For resolving XML's limitations, we use binary XML and evaluate XML. Through evaluation, we found that when using binary XML, although additional time is required, it can reduce the process time and improve performance of XML messaging system.

\section{References}

[1] D. Alberts, J. Garstka and F. Stein. "Network centric warfare: Developing and leveraging information superiority," CCRP, 1999.

[2] W. Perry, R. Button, J. Bracken, T. Sullivan, and J. Mitchell, "Measures of Effectiveness for the Information-Age Navy," RAND, pp.2, 2002.

[3] Baker, B. "Combined Interoperability Test Plan (CITP) for Tactical Data Links (TDL) and United States Message Text Format (USMTF)," U.S. Defense Information Systems Agency, April. 2007.

[4] J. Kim, S. Kim, M. Lim, "Overview of Tactical Data Link Technology," Journal of KIISE : New Technology for Defense, Vol. 25, No. 9, pp. 18-27, Sept. 2007. 
[5] A Thomas, T. Turner and S. Soderlund, "Net-Centric Adapter for Legacy Systems," System Journal of IEEE, Vol. 3, No 3, pp. 336-342, Sept. 2009.

[6] W. Burkett, "Product data markup language: a new paradigm for product data exchange and integration," Computer-Aided Design, Vol. 33, No. 7, pp. 489-500, 2001

[7] T. Bray, D. Hollander, A. Layman, R. Tobin, H Thompson, "Namespaces in XML 1.0," W3C Recommendation, Dec. 2009.

[8] K. Swanson and J. Judt, "CompreX: XML Compression applied to the Airborne Internet," NASA ICNS Conference and Workshop, May. 2005.

[9] J. Kangasharju, T. Lindholm and S. Tarkoma, "XML Messaging on Mobile Devices: From Requirements to Implementation," Computer Networks, Vol. 51, No. 16, pp. 4634-4654, 2007.

[10] P. Sandoz and S. Pericas-Geertsen, "Fast Infoset @ Java.net," Proc. XTech2005, May. 2005.

[11] J. Schneider and T. Kamiya, "Efficient XML Interchange (EXI) Format 1.0," W3C Candidate Recommendation, Dec. 2009.

[12] M. Cokus and S. Perica-Geertsen, "XML Binary Characterization Use Cases," W3C Working Group Note, Mar. 2005.

[13] D. Peintner and S. Pericas-Geertsen, "Efficient XIL Interchange (EXI) Primer," W3C Working Draft, Dec. 2009.

[14] G. Moritz, D. Timmermann, R. Stoll and F. Golatowski, "Encoding and Compression for Devices Profile for Web Services," 5th International Workshop on Service Oriented Architectures in Converging Networked Environments (SOCNE2010), 2010.

[15] International Telecommunication Union(ITU), Recommendation X.891, Generic Applications of ASN.1-Fast Infoset, 2005

[16] G. White, D. Brutzman, S. Williams, "Efficient XML Interchange Measurements Note," W3C Working Draft, Jun. 2006.

[17] M. Bayer, "Analysis of Binary XML Suitability for NATO Tactical Messaging," M.S. Thesis,
Naval Postgraduate School, Monterey, CA USA, Sept. 2005.

[18] F. Tian, B. Reinward, H. Poraheshm T. Mayr, J. Myllymaki, "Implementing A Scalable XIL Publish/Subscribe System Using Relational Database Systems," In SIGMOD, 2004.

[19] Why The Air Force Needs Binary XML, http://www.mitre.org/news/events/xml4bin/pdf /gilligan_keynote.pdf

[20] Sea Power for a New Era 2007, http:// www.navy.mil/navydata/policy/seapower/spne 07/chap3-07_sea_forcenet.pdf

[21] Common Link Integration Processing, http:// www.is.northropgrumman.com/products/comm on_link_integration_proces/assets/CLIP.pdf

[22] Data Links and Tactical Messaging nteroperability Hub, http://ww-903.ibm com/ kr/event/dow nload/200804_336/s336_b02.pdf

[23] C. Stinson, "Intemet Protocol(IP) Over Link-16," M.S. Thesis, Air Force Institute of Technology, Ohio, USA, Mar. 2003.

[24] MACE31501 Aircraft Group Design, http://personalpages.manchester.ac.uk/staff/D ominic.Diston/MyTeaching/MACE31501/MACE 31501.3.pdf

[25] J. Seo, J. Yang, J. Jin, H. Choi, "A suggenstion for the XML based Tactical Data Link Common Software Architecture," 12th Conference on Communications Electronic, pp. 7-12, Seoul, Korea, Sept. 2008.

[26] M. Ra, K Yang, "Extraction of Military Ontology Using Six-Step Bottom-up Approach," Journal of The Korea Society of Computer and Information, Vol. 14, No. 6, Jun. 2009.

[27] W. Aalst and A. Kumar, "XML based schema definition for support of inter-organizational workflow, Information Systems Research 14, pp. $23-47,2003$.

[28] S. Lee, J. Lim, K. Joo, "Design a XML DBMS using RDBMS Based on XML Schema ," Journal of The Korea Society of Computer and Information, Vol. 9, No. 4, Dec. 2004. 


\section{저 자 소 개}

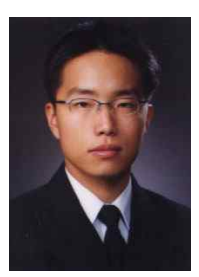

김 홍 재

2003 : 해군사관학교 전산과학과 이학사

2009 - 현재 :

아주대학교 NCW학과 통합과정

관심분야 : SOA, XML, 미들웨어,

$$
\text { 클라우드컴퓨팅 }
$$

E-mail : carrotbox@ajou.ac.kr

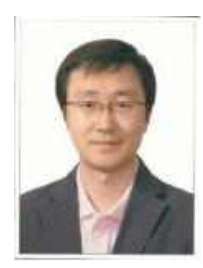

오 상 윤

2006 : 미 인디애나대학교 전산학 박사

2006 - 2007 : SK 텔레콤

2008 - 현재 :

아주대학교 정보 및 컴퓨터공학과 조교수

관심분야 : 웹/분산 시스템, $\mathrm{SOA}$,

$\mathrm{Ad}-\mathrm{hoc} / \mathrm{P} 2 \mathrm{P}$ 시스템,

클라우드 컴퓨팅

E-mail : syoh@ajou.ac.kr 